\title{
A General Model of E-learning for Supporting Blended Learning in Higher Education
}

\author{
Jinghua Zhang \\ Department of Computer \\ North China Electric Power University (Baoding), NCEPU \\ Baoding, China
}

\begin{abstract}
The blended learning which combines the elearning and traditional classroom teaching is becoming the trend in higher education. There has been a lot of research concentrated on the practice of blended learning which just shows the diversity of practice mode of blended learning. This paper pays great attention to the e-learning for supporting blended learning in higher education throughout the entire teaching and learning process. To adapt to the diversity, a general model of blended learning about instructional design and process is given. Based on it, the e-learning model is given also. With the e-learning model, many practice forms of blended learning can be expressed, and the whole process of teaching and learning can be supported.
\end{abstract}

Keywords-Blended learning; Higher education; E-learning; Instructional design

\section{INTRODUCTION}

E-learning generally refers to the network education. It has a wide range in application, such as distance education, training of company or enterprise, learning community and so on. But e-learning can also play an important role in campus. At present, the consensus of the international educational technology field is that the combination of classroom teaching and e-learning can make them complement each other and obtain the better learning effect. In this context, blended learning is widely concerned by educators all over the world. In higher education, a lot of research has been concentrated on the practice for specific courses or effectiveness comparison [1, 2, 3]. JiTT mode is just a blended learning practice form [4]. Flipped classroom mode is a hot research topic recently $[5,6]$, and it is also a practice mode of blended learning. There are also other forms for blended learning given by some studies for specific courses [1, 7]. Reference [7] give a case study of three courses with different types of blend to discuss how the blend supports student learning. These practices indicated that the practice form of blended learning is of diversity, and it is a difficult for e-learning environment to support the whole process of teaching and learning of blended learning mode. This paper pays great attention to the general model of blended learning which is the basis of a general e-learning environment for the whole teaching and learning process of various blended learning mode, and then an e-learning model is given according to the general model.

\section{The Practice Mode OF BLENDED LEARNING}

The traditional network education platform of university is only used as an aided tool for management of students, notices, resources, assignments and so on. So, the traditional network platform cannot be regarded as e-learning. E-learning can do more for university course. There are some different practice forms for blended learning which have changed the traditional teaching mode by appropriate use of the e-learning. To sum up, there are three typical patterns on how to blend the classroom teaching and e-learning.

\section{A. Pattern One: Supplementary Mode}

This mode makes e-learning as a supplement of classroom teaching. Since classroom teaching is based on the class, the lecture can only adapt to part of the students demands. On the other hand, there still leave some problems unresolved in class as the time limit which need students learning by themselves after class. With E-learning, abundant resources can be provided, such as examples, exercises, courseware, videos, and so on. As a remedy, students can learn through all kinds of resources, and personalized instruction and recommendation can be provided to aid the students learning. In this mode, elearning system should be interrelated with the course schedule and give adaptive remedy according the learning state of student.

\section{B. Pattern two: JiTT Mode}

JiTT is just-in-time teaching mode [4], which gives a new idea greatly different to the traditional classroom teaching. The teacher assigns the task before classroom, and the students give the feedback, then the teacher decides the contents in class. The essence of JiTT is a feedback loop of extracurricular preparation and classroom activities, and classroom activities are decided by the extracurricular preparation. Its main goal is to use the students' feedback to guide classroom teaching and stimulate the student's learning motivation. In this mode, elearning is used to support the feedback loop.

\section{Pattern Three: Flipped Classroom Mode}

Flipped classroom mode is also an innovation for traditional classroom teaching. The idea is flipping the traditional learning process. The students complete the knowledge learning autonomously in extracurricular time, and 
the traditional classroom teaching changes its role as the interaction channel between teacher and students. The classroom teaching is mainly used to answer doubts, discuss problems, report outcomes and so on. This mode changes the role of students and teachers, and the students become the principal part and the teacher becomes the helper and facilitator The mode can strengthen the initiative and creative of students. In this mode, e-learning is used to teach the knowledge by videos and other resources.

\section{Summarize}

The three modes are all the practice modes of blended learning. They all embody the blending. Blended learning is to combine the advantages of traditional classroom teaching and e-learning. The merits of classroom teaching come from face to face communication which can bring the flexibility of instruction; and the merits of e-learning are abundant resources, flexible and timely interaction, autonomous and personalized learning. The three modes give the different combination of classroom teaching and e-learning and have their own advantages and disadvantages. For the diversity of curriculum and curriculum knowledge point, the appropriate instructional mode is not only one form. Blended learning is guiding ideology of modern higher education, but the practice may be various, we need to summarize a general model which can be used by e-learning to support all kinds of blended learning.

\section{General Model of BLENDED LEARNING}

E-learning can bring many new features for university course. It can provide abundant resources and personalized recommendations which classroom teaching cannot afford. Some learning elements and activities can have several organization forms. For example, discussion and communication can be performed in class or in network; exercise can be completed in class, outside class, or online in network. E-learning can also support the task assignment and student feedback with which the relationship between learning tasks can be established. So, e-learning may bring many new thoughts and strategies of pedagogy.

Since the initial thought of blended learning is combination of classroom teaching and e-learning, but some research suggested to enlarge the definition by combination of not only the classroom and network environments, but also various technologies, various pedagogies and so on $[3,8,9]$. So, as the general model, we take the classroom and network as environment factors, and the emphasis of blended learning model is the combination of all kinds of teaching elements, teaching strategies, teaching activities and so on, and selection of environments between classroom and network in order to take good advantage of the merits of classroom teaching and network learning.

For implementing blended learning in higher education, elearning is one important part, and the blended instructional design is another important part.

\section{A. Instructional Design Model of Blended Learning}

Instructional design is a complex and comprehensive thinking activity of teacher. Teaching is not only to impart the knowledge to students, but also to help students learn better through various teaching and learning methods. Blended learning highlights the diversity of combination with a variety of teaching elements, teaching activities, teaching strategies to help students build their knowledge better. E-learning makes the diversity possible. The instructional design based on the blended learning can have more choices to give the combination, and help students learn from many aspects. The blended instructional design involves several points.

\section{1) First Point}

The guiding ideology of teaching is the basis. The goal of the course should be decided such as foundation of knowledge, practical ability, self-learning ability, innovation ability or the combination of them. The goal will affect design decisions. Nowadays, university education emphasizes the cultivation of practical ability and innovation ability of students.

\section{2) Second Point}

The teaching strategy is an important part of the whole instructional design. Good teaching strategies can make students understand more easily, and arouse student interest and stimulate student enthusiasm. There are some general teaching strategies which can be taken into account for specific course. Some teaching strategies focus on the teaching method of the course contents, such as problem based teaching, project driven teaching, task driven teaching, case teaching, etc. Collaborative learning and inquiry learning focus on the special way of practice. The JiTT mode and flipped classroom model emphasizes the allocation of teaching elements before, during or after class. According to the characteristics of the course and the characteristics of the knowledge point, the teacher should choose the appropriate teaching strategies, or design special teaching strategies. The emphases of these teaching strategies are different, and the teaching strategies of different angles can be combined with each other to get better teaching effect. Such as the problem-based teaching strategy, the teacher design a problem to guide the student's thinking and then led to the knowledge point. If JiTT mode is combined with the strategy, the problem can be provided before class in e-learning system, and student can do preview and give feedback, so the classroom teaching can be adjusted to grasp the student's problems precisely. This is also the idea of blending.

\section{3) Third Point}

Design the teaching elements under the guidance of teaching strategy, such as knowledge learning, example, exercise, assignment, project, discussion, inquiry subject, etc. For example, case teaching strategy need to design suitable teaching cases. The problem based strategy need to design problems. Collaborative learning requires the design of collaborative task. With the help of e-learning system, the teaching elements can be provided more than traditional class and the combination of the elements with some pedagogy thoughts is helpful for students learning.

\section{4) Fourth point}

Design the manner of teaching. The teaching elements can be performed through many ways, such as the knowledge learning can be classroom teaching or video in e-learning; the practice project can be performed step by step, or by group, or by individual. Others like how to organize the exercises, 
project report, and discussion and so on should be decided according the teaching strategy and guiding ideology.

\section{5) Fifth Point}

Design the learning tasks or activities. According to the manner decided, the corresponding activity or task should be designed such as discussion activity, pre-class task, and exercise activity and so on.

\section{6) Sixth Point}

Design the evaluation method of students. The evaluation factors and model should be decided to get a Comprehensive evaluation.

\section{B. Process Model of Blended Learning}

The process model of blended learning is described in Fig.1.

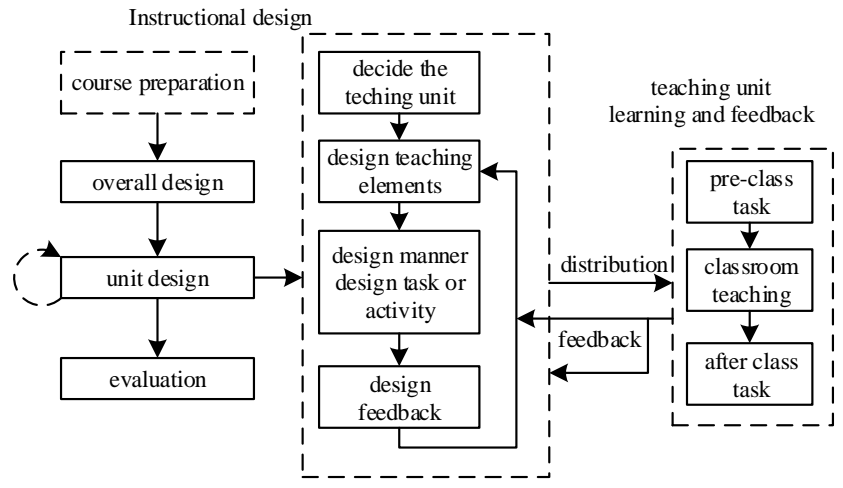

Fig. 1. Process model of blended learning

\section{1) Prepare of the Course}

The teacher analyzes the course, constructs the knowledge structure, and designs the objectives of knowledge point. Since many courses need to cultivate the practice ability, the objectives of practice ability should also be designed.

\section{2) The Overall Instructional Design}

The general course teaching involves two aspects: the teaching of knowledge points and the cultivation of practice ability. The overall teaching strategy can also be designed from the two aspects. According to the objectives of the course, the overall design can be determined at first, such as the teaching strategies and teaching mode, the global project or example and so on.

Teaching the knowledge points and cultivating the practice ability can be mixed together or separated. Such as task driven or project driven teaching strategy can combine the knowledge and practical in an activity of classroom teaching, so that the two aspects were resolved simultaneously. This kind of teaching strategy can also be combined with JiTT mode to be divided into pre-class and in-class activities, it is still a mixed form. But the flipped classroom mode separates knowledge from practice by completely separated activities. Different decision embodies the different instructional idea, and has its applicability.

\section{3) The Unit Design}

Decide the teaching unit, and design the elements, manners, and tasks (activities). Assign the task or activity to different stage (pre, in, after class) and construct the teaching cycle of the unit.

\section{4) Learning and Feedback}

According to the students' feedbacks, teacher can adjust the classroom teaching activity on contents or add extra element and activity within the teaching unit, or adjust instructional design of next teaching unit.

\section{5) Student Evaluation}

Collect the student learning records and feedbacks as a factor of evaluation.

\section{E-LEARNING MODEL FOR SUPPORTING BLENDED LEARNING}

Blended learning needs e-learning as the network environment. The instructional design based on blended learning need to be expressed on e-learning to get a timely and flexible interaction between teacher and students. So, we think the e-learning is not only a network part of blended learning, but the whole organization and controlling of the process of teaching and learning. In order to support the diversity of blending learning, the general model must be expressed in elearning. Taking the e-learning as the environments, the teacher can do the instructional design and monitoring to aided the student learning, and the student acquires the teacher's instruction, and learns autonomously (such as learning resources, participating the activity, finishing the task and giving feedback).

For the e-learning model supporting blended learning, we just add a new layer on traditional e-learning to express the blended learning model. So, the traditional characteristics still preserve, such as abundant resources, the students learning situation, and personalized accommodation of resource. And new functions are also provided to support real time instruction by teacher's instructional design. The e-learning model is described in Fig. 2.

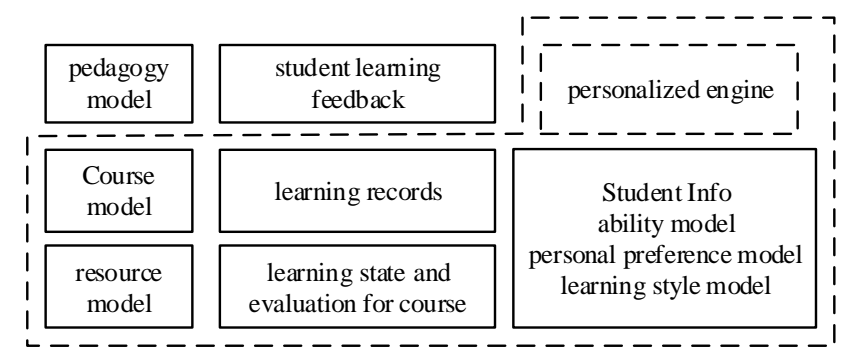

Fig. 2. E-learning mode

\section{A. Traditional E-learning Model}

In Fig. 2, the part surrounded by dotted line is the traditional e-learning model. At first, the resource model is the basis of e-learning. Both the traditional e-learning and blended learning in university both need abundant resources. For example, the knowledge point teaching resources can be video, PPT, html for different student and different purpose, and elearning can provide many examples with different difficulty 
degrees. So, a resource model is necessary for resource description. Course model is used to describe the course with knowledge structure, knowledge point illustration, and learning objective. The relationship between resource and knowledge point should be described as part of the resource model. Elearning should construct the student model including student information, student learning records, student learning state and evaluation about a course. Other student information is also needed to support the personalization such as ability model, personal preference model, learning style model. Then the personalized inference engine can be used to do the recommendation or give instruction.

\section{B. The Layer for Blended Learning Model}

In Fig. 2, the part beyond the dotted line is the new design for blended learning including the instructional design and student learning feedback.

\section{1) Instructional design model}

The instructional design model consists of four levels: task line, teaching unit, task point and task requirements which represent the instructional design of teacher.

a) Task Line. Task Line represents the overall design of teaching, and a task line represents the teaching task flow. According to the course, Teacher can build up one or more task lines for specific topics representing the parallel teaching tasks.

b) Teaching Unit. Each task line has many nodes, and a node represents a teaching unit, and the teaching unit is connected with the course model. A teaching unit may contain one or more knowledge points or practical objectives. The specific teaching plan for the teaching unit is expressed by task points in the teaching unit.

c) Task Point. A task point is a combination of teaching elements, teaching environment, and teaching manner. There are multiple task points combined in a teaching unit with sequential or parallel relationship. A task point can be seen as a learning task or a teaching activity. The teacher gives the description of the task point and gives the purpose of it also. Different teaching elements are represented by the task type: knowledge learning, case analysis, thinking problem, discussion, assignment, test, project design, research topic, resource reading, etc. The task properties are used to describe the execution manner such as environment (classroom, network), task relationship (pre-class preparation, classroom teaching, after-class practice), task organization (personal task, group task, all class task) (whole task, task divided by segments), task type (knowledge learning task, practice task) (must task, optional task) and so on. Classroom teaching can be regarded as an important task which is integrated into the whole instructional design. d) Task requirements. The task requirements are the resources, feedbacks (including feedback information, document and others), communication or collaboration activities in network needed by the task point.

\section{2) Student Feedback Model}

Some task point need student give feedback. Student's feedback for blending learning is a part of the student model and should be recorded. The feedback can be designed a combination of standardized and non-standardized forms. It can be used by teacher to adjust the subsequent design, used by system to support personalization. It can also be useful to evaluation of students.

\section{CONCLUSION}

E-learning plays an important role in blended learning of higher education. Blended learning can have a variety of forms, so the requirements to e-learning are also different. This elearning model is suitable for the three modes mentioned in this paper. It is also extensible to support other special forms, and adapt to the variety of blended learning. At the same time, it retains the traditional characteristics of e-learning. Under the model, the whole process of teaching and learning can be expressed in e-learning, and can change the traditional operation pattern in higher education with all in network.

\section{REFERENCES}

[1] A. Yasemin, "Exploring the effectiveness of blended learning in interior design education," Innovations in Education and Teaching International, Vol. 53, no.5, pp.508-518, 2016.

[2] F. Alonso, D. Manrique, L. Martínez, and J.M. Viñes, "How Blended Learning Reduces Underachievement in Higher Education: An Experience in Teaching Computer Sciences," IEEE Transactions on Education, Vol. 54, no.3, pp.471-478, Aug. 2011.

[3] N. Hoic-Bozic, V. Mornar, and I. Boticki, "A blended learning approach to course design and implementation," IEEE Transactions on Education, vol. 52, no. 1, pp. 19-30, Feb. 2009.

[4] Just-in-Time Teaching. http://134.68.135.1/jitt/.

[5] C.F. Herreid, and N.A. Schiller, "Case Study: Case Studies and the Flipped Classroom,” Journal of College Science Teaching, Vol. 42, no.5, pp.62-67, 2013.

[6] S.J. DeLozier, and M.G. Rhodes, "Flipped Classrooms: a Review of Key Ideas and Recommendations for Practice," Educational Psychology Review, Vol. 29, no.1, p.141-151, March, 2017.

[7] M. Lai, K.M. Lam, and C.P. Lim, "Design principles for the blend in blended learning: a collective case study," Teaching in Higher Education, Vol. 21, no.6, pp.716-729, 2016.

[8] N. Hoic-Bozic, M. H. Dlab, and V. Mornar, "Recommender System and Web 2.0 Tools to Enhance a Blended Learning Model," IEEE Transactions on Education, Vol. 59, no. 1, pp.39-44, 2016.

[9] C. R. Graham, W. Woodfield, and J. B. Harrison, "A framework for institutional adoption and implementation of blended learning in higher education," Internet and Higher Education, vol. 18, pp. 4-14, Jul. 2013. 